\title{
Diagnosis of Pneumocystis carinii pneumonia: specificity and sensitivity of polymerase chain reaction in comparison with immunofluorescence in bronchoalveolar lavage specimens
}

\author{
ENRICA TAMBURRINI, PAOLA MENCARINI, A. DE LUCA, G. MAIURO, G. VENTURA, \\ A. ANTINORI, ADRIANA AMMASSARI, ELENA VISCONTI, L. ORTONA, \\ ALESSANDRA SIRACUSANO*, ELENA ORTONA* and G. VICARI*
}

Department of Infectious Diseases, Università Cattolica and *Department of Immunology, Istituto Superiore Sanità, Rome, Italy

\begin{abstract}
Summary. DNA amplification by the polymerase chain reaction (PCR) is a promising method for the detection of Pneumocystis carinii in immunosuppressed patients. The sensitivity and specificity of the PCR technique has been assessed in comparison with the immunofluoresence method (IF) on bronchoalveolar lavage fluid (BALF). Results correlated in $43(78.8 \%)$ of 52 cases studied. $P$. carinii PCR gave positive results with BALF from all 32 patients found to have $P$. carinii pneumonia (PCP); IF gave positive results with 26 of them. PCR was more sensitive and as specific as IF. However, at the present time, we do not believe that it is clinically useful for detection of $P$. carinii in BALF samples. $P$. carinii DNA amplification by PCR should be reserved for testing IF-negative BALF samples from patients judged clinically to have PCP.
\end{abstract}

\section{Introduction}

Pneumocystis carinii pneumonia (PCP) is one of the most frequent opportunist infections in AIDS patients. Although its incidence is declining and its mortality rate is decreasing, PCP still represents a crucial event during AIDS disease. ${ }^{1}$ The extensive use of prophylaxis has changed the clinical presentation of PCP..$^{2-5}$ Thus, it is important to have a method for the detection of $P$. carinii infection in HIV-infected patients on prophylaxis, when micro-organisms in the bronchoalveolar lavage fluid (BALF) are very few and show some staining peculiarities, and the clinical features of PCP are unusual. ${ }^{2,6}$ Moreover, a rapid, sensitive and specific diagnostic technique is required for the detection of $P$. carinii infection in patients with only mild symptoms of respiratory failure.

Recently, Wakefield et al. have developed a highly specific and sensitive technique for the identification of $P$. carinii by polymerase chain reaction (PCR) amplification of DNA in BALF $^{7}$ and induced sputum. ${ }^{8} \mathrm{~A}$ strong signal in the PCR (ethidium bromide and oligoblotting positive) was consistent with a diagnosis of PCP; a weak signal (oligoblotting positive alone) indicated subclinical pulmonary colonisation. ${ }^{9}$

The primary aim of our study was to assess the sensitivity, specificity, positive predictive value, nega- tive predictive value and accuracy of the PCR technique on BALF as compared to the indirect immunofluorescence (IF) method for the detection of $P$. carinii infection in immunosuppressed patients. A secondary aim was to investigate the relationship between the result of a "quantitative" PCR for $P$. carinii and the clinical presentation of PCP.

\section{Materials and methods}

\section{Patients and clinical specimens}

BALF samples were obtained from 52 immunosuppressed patients (39 male, 13 female; age range 24-58 years) at the Department of Infectious Diseases, Università Cattolica, Rome; 48 had HIV infection. three were being treated for lymphoma and one was hypogammaglobulinaemic (with a selective deficit of IgA and IgM). Forty-nine patients underwent bronchoscopy for an acute respiratory illness (fever, cough, shortness of breath) with one or more of the following features: abnormal chest signs, arterial hypoxaemia, abnormal chest X-ray. Three HIV-infected patients underwent bronchoscopy to investigate the presence of a pulmonary Kaposi's sarcoma.

Bronchoalveolar lavage was performed by two different operators who used the same technique:10 $10 \mathrm{ml}$ of lukewarm saline $(\mathrm{NaCl} 0.9 \%)$ were instilled 
into the middle lobe and the lingula with an Olympus fibre-optic bronchoscope; after $60 \mathrm{~s}$, a lavage sample was recovered corresponding to $50-65 \%$ of the instilled volume. BALF samples were processed for microbiological and cytological analysis and a sample was stored at $-20^{\circ} \mathrm{C}$ until required for PCR.

\section{Indirect immunofluorescence}

Indirect immunofluorescence (IF) with monoclonal antibodies (MAbs) specific for antigens of the cyst wall (Monofluokit P. carinii, Diagnostics Pasteur, Paris, France) was performed according to the manufacturer's instructions. The dried smears were overlaid with $20 \mu \mathrm{l}$ of trypsin and incubated at $37^{\circ} \mathrm{C}$ for $30 \mathrm{~min}$ in a humidified chamber. They were rinsed and then overlaid with $20 \mu \mathrm{l}$ of anti- $P$. carinii mouse MAb. The slides were incubated at $37^{\circ} \mathrm{C}$, rinsed and overlaid with $20 \mu \mathrm{l}$ of fluorescein isothiocyanate-conjugated antimouse antibody. After a final rinse, the smears were examined by fluorescence microscopy. The IF test was considered to be positive if five or most cysts were detected on a smear.

\section{$P$. carinii $D N A$ amplification by $P C R$}

Briefly, $20 \mu$ of BALF samples were digested with proteinase $\mathrm{K}$ (Sigma; $0.5 \mathrm{mg} / \mathrm{ml}$ final concentration) in the presence of $10 \mathrm{~mm}$ Tris- $\mathrm{HCl}(\mathrm{pH} \mathrm{8.3}), 50 \mathrm{~mm}$ $\mathrm{KCl}, 1.5 \mathrm{mM} \mathrm{MgCl}_{2}$ and SDS $0.25 \%$ for $2 \mathrm{~h}$ at $56^{\circ} \mathrm{C}$. In 20 cases, phenol-chloroform extraction and ethanol precipitation $^{11}$ was also performed but no appreciable advantage was observed with this protocol and it was not used with the remaining 32 specimens; when this step was omitted, proteinase $\mathrm{K}$ was inactivated by heating the digested samples at $95^{\circ} \mathrm{C}$ for $10 \mathrm{~min}$. A $45-\mu \mathrm{l}$ volume of buffer containing $100 \mathrm{~mm}$ Tris- $\mathrm{HCl}$ (pH 8.3), $500 \mathrm{mM} \mathrm{KCl}, 15 \mathrm{mM} \mathrm{MgCl}_{2}$ and gelatin $0.01 \% \mathrm{w} / \mathrm{v}$ was added; $5 \mu \mathrm{l}$ of this mixture (equivalent to $1 \mu \mathrm{l}$ of a clinical specimen) was used for DNA amplification. An oligonucleotide primer pair (pAZ 102-E and pAZ102-H), which amplifies a $P$. carinii DNA sequence of part of the gene coding for the large subunit of mitochondrial ribosomal RNA, ${ }^{712}$ was used. Oligonucleotides were synthesised at the Institute of Genetics, Università Cattolica, Rome. For amplification, $100 \mathrm{pmol}$ of primers were used in a $100 \mu$ volume of amplification buffer containing (final concentrations) $10 \mathrm{~mm}$ Tris- $\mathrm{HCl}, 50 \mathrm{~mm} \mathrm{KCl}, 4 \mathrm{~mm}$ $\mathrm{MgCl}_{2}, 0.2 \mathrm{~mm}$ dNTPs (Perkin Elmer-Cetus, Norwalk, CT, USA), Taq DNA polymerase (Perkin ElmerCetus) 2.5 units. A "hot start" technique was used and 38 cycles of $94^{\circ} \mathrm{C}$ for $90 \mathrm{~s}$ (denaturation), $55^{\circ} \mathrm{C}$ for $90 \mathrm{~s}$ (annealing) and $72^{\circ} \mathrm{C}$ for $2 \mathrm{~min}$ (extension), with a final extension at $72^{\circ} \mathrm{C}$ for $5 \mathrm{~min}$, were performed in a thermal cycler (Perkin Elmer-Cetus).

A 5- $\mu$ l volume of amplification solution was electrophoresed in an agarose $2 \%$ gel containing ethidium bromide $0.5 \mu \mathrm{g} / \mathrm{ml}$ and the 346-bp amplification product was visualised with an ultraviolet transilluminator.
The amplification product was also blotted on to a nylon filter (Hybond N, Amersham, Sydney, Australia) and hybridised with a ${ }^{32} \mathrm{P} 5^{\prime}$-end-labelled oligonucleotide specific for human derived $P$. carinii. $^{713}$ After high stringency washes, the product was visualised by overnight exposure to an XAR-5 film (Eastman Kodak, Rochester, NY) at $-70^{\circ} \mathrm{C}$ with intensifying screens.

The sensitivity of the technique was tested by adding serial dilutions of murine $P$. carinii organisms to a PCR-negative BALF. The cyst:trophozoite ratio of the preparation was found to be $1: 10$ based on Giemsa staining and the average number of nuclei was $1.44 \times$ $10^{6} / \mu 1$. Samples were processed as above, and the amplification product was electrophoresed on an agarose $2 \%$ gel containing ethidium bromide. The amplification product was blotted and hybridised with an anti-sense oligonucleotide (5'-CCA GCT ATA TCC TAG TCC GA-3') specific for both rat and human derived $P$. carinii. $^{13}$ A signal was detectable for samples containing $\geqslant 10$ nuclei $/ \mu$ of BALF by ethidium bromide and $\geqslant 1$ nucleus/ $\mu$ l of BALF by oligoblotting.

All pre-PCR steps were performed in a laminar flow cabinet, and laboratory procedures to avoid contamination were strictly applied. All experimental stages were performed in duplicate; multiple negative controls (including bronchoscope washing fluid) were included in each amplification run.

\section{Statistical methods}

Sensitivity, specificity, positive predictive value, negative predictive value and accuracy of PCR and IF results for the detection of $P$. carinii in BALF were calculated from a $2 \times 2$ table. $^{14}$ The statistical significance of differences in the sensitivities and specificities of the two methods was calculated by McNemar's test. ${ }^{15}$

\section{Results}

On the basis of clinical data, response to treatment and results of laboratory investigations (including IF for $P$. carinii and microbiological and cytological investigations on BALF and post-mortem lung samples), the 52 patients were classified as follows: group A-26 immunosuppressed patients (24 HIVpositive and two HIV-negative) with $P$. carinii pneumonia diagnosed by IF and response to treatment; group B-four patients (three HIV-positive and one HIV-negative) with $P$. carinii pneumonia diagnosed by response to treatment but IF negative; group $\mathrm{C}$ - two HIV-positive patients with $P$. carinii pneumonia diagnosed by autopsy but IF negative and response to treatment not evaluable; group D-17 patients (16 HIV-positive and one HIV-negative) without $P$. carinii pneumonia, negative by IF, with no response to treatment and an alternative aetiological cause for the 
Table I. DNA amplification and immunofluorescence for $P$. carinii in BALF; comparison with response to treatment

\begin{tabular}{|c|c|c|c|c|c|c|c|}
\hline \multirow{2}{*}{$\begin{array}{l}\text { Classification } \\
\text { of patients }\end{array}$} & \multirow{2}{*}{$\begin{array}{l}\text { Number of } \\
\text { patients }\end{array}$} & \multirow{2}{*}{$\begin{array}{l}\text { IF } \\
\text { result }\end{array}$} & \multirow[b]{2}{*}{ Autopsy } & \multirow{2}{*}{$\begin{array}{l}\text { Response } \\
\text { to treatment }\end{array}$} & \multicolumn{3}{|c|}{ Number of BALF samples with PCR result } \\
\hline & & & & & $\mathrm{EB}+\mathrm{OB}+$ & $\mathrm{EB}-\mathrm{OB}+$ & $\overline{\mathrm{EB}-\mathrm{OB}-}$ \\
\hline Group A & 26 & + & $\ldots$ & + & 21 & 5 & 0 \\
\hline Group B & 4 & - & $\ldots$ & + & 3 & 1 & 0 \\
\hline Group C & 2 & - & positive & NE & 2 & 0 & 0 \\
\hline Group D & 17 & - & negative* & - & 0 & 0 & 17 \\
\hline Group E & 3 & - & $\mathrm{NA} \dagger$ & - & 0 & 3 & 0 \\
\hline
\end{tabular}

NA, not available; NE, not evaluable; $\mathrm{EB}$, ethidium bromide; $\mathrm{OB}$, oligoblotting.

*Ten patients alive.

†One patient alive.

Table II. DNA amplification and immunofluorescence for $P$. carinii on BALF of 32 patients with PCP: influence of specific prophylaxis

\begin{tabular}{|c|c|c|c|c|c|}
\hline \multirow{2}{*}{ Treatment } & \multirow{2}{*}{ Number of cases } & \multirow{2}{*}{$\mathrm{IF}+$} & \multicolumn{3}{|c|}{ Number of BALF samples with PCR result } \\
\hline & & & $\mathrm{EB}+\mathrm{OB}+$ & $\mathrm{EB}-\mathrm{OB}+$ & $\mathrm{EB}-\mathrm{OB}-$ \\
\hline Episode I & 28 & & & $\ldots$ & $\ldots$ \\
\hline $\begin{array}{l}\text { No prophylaxis } \\
\text { Prophylaxis }\end{array}$ & 22 & 17 & 21 & 1 & 0 \\
\hline AP & 1 & 0 & 0 & 1 & 0 \\
\hline CTX & 1 & 1 & 0 & 1 & 0 \\
\hline$D+P$ & 4 & 4 & 3 & 1 & 0 \\
\hline total & $\ldots$ & 22 & 24 & 4 & 0 \\
\hline Episode II & 4 & $\ldots$ & $\ldots$ & $\ldots$ & $\ldots$ \\
\hline AP & 3 & 3 & 2 & 1 & 0 \\
\hline$D+P$ & 1 & 1 & 0 & 1 & 0 \\
\hline total & $\ldots$ & 4 & 2 & 2 & 0 \\
\hline Total & 32 & 26 & 26 & 6 & 0 \\
\hline
\end{tabular}

AP, aerosolised pentamidine $300 \mathrm{mg}$ every 4 weeks; CTX, co-trimoxazole one double strength tablet every second day; D +P, dapsone $100 \mathrm{mg}$ weekly plus pyrimethamine $25 \mathrm{mg}$ twice weekly.

respiratory disease; group E-three patients (HIVpositive) with negative IF and response to non-specific treatment (table I). Thus, 32 patients (groups $\mathrm{A}+\mathrm{B}+\mathrm{C}$ ) were ultimately found to have PCP; 28 of them experienced a first episode of PCP (six were on prophylaxis), and the remaining four experienced a relapse 3-16 months after initial PCP diagnosis. Of the 20 patients judged to be free of PCP (groups D E E), 13 were on specific prophylaxis.

The results of $P$. carinii DNA amplification are reported in table I. Samples from all patients with PCP gave positive results by $P$. carinii DNA amplification by PCR (by oligoblotting, with or without ethidium bromide); samples from 17 patients without PCP gave negative results by PCR (both ethidium bromide and oligoblotting). Samples from three patients judged to be free of PCP gave positive results by PCR after oligoblotting. The first of these patients died from a heroin overdose and autopsy was not available; however, pulmonary disease was attributed to $\mathrm{Myco}$ bacterium tuberculosis (identified on BAL) and disseminated Staphylococcus aureus infection with lung micro-abscesses. The second patient died from respiratory and myocardial failure probably due to $M$. tuberculosis, 4 months after BAL; he was receiving anti- $P$. carinii prophylaxis with co-trimoxazole (one double-strength tablet every second day); autopsy not authorised. The third patient, an intravenous drug abuser and a smoker ( $>25$ cigarettes daily) who suffered from recurrent episodes of bacterial pneumonia, remained alive; 10 months after BAL, a chest X-ray showed a pattern of chronic bronchitis; subsequently feeling well and on PCP prophylaxis with pyrimethamine (50 $\mathrm{mg}$ weekly) and dapsone $(50 \mathrm{mg}$ daily), her CD4 + cell count was $138 / \mathrm{mm}^{3}$.

In table II, $P$. carinii DNA amplification (PCR) results on the BALF samples from the 32 patients with PCP are related to the clinical data and $P$. carinii prophylaxis. Including the three immunosuppressed patients without $\mathrm{HIV}$ infection, 22 patients experienced PCP without primary prophylaxis; BALF samples from $21(95.4 \%)$ gave positive $P C R$ results by ethidium bromide and oligoblotting and one gave a positive result by oligoblotting alone. Ten HIV patients experienced PCP on prophylaxis (aerosolised pentamidine in four cases, co-trimoxazole in one and pyrimethamine +dapsone in five) as reported by Antinori et al. ${ }^{16}$ BALF samples from five patients $(50 \%)$ gave positive PCR results by ethidium bromide and oligoblotting and five by oligoblotting alone.

Results obtained by IF and by PCR correlated in 43 $(78.8 \%)$ of 52 cases studied; discrepant results included nine IF-negative BALF samples (six from patients with PCP and three from patients without 
Table III. Diagnostic value of DNA amplification and immunofluorescence on BALF of patients with PCP

\begin{tabular}{lccc}
\hline & \multicolumn{3}{c}{ PCR } \\
\cline { 3 - 4 } Criterion & IF & EB + OB + & OB + alone \\
\cline { 3 - 4 } & & $81 \cdot 2$ & 100 \\
Sensitivity & $81 \cdot 2$ & 100 & 85 \\
Specificity & 100 & 100 & $91 \cdot 4$ \\
Positive predictive value & 100 & 76.9 & 100 \\
Negative predictive value & 76.9 & 88.5 & 94.2 \\
Accuracy & 88.5 & & \\
& & &
\end{tabular}

PCP) that gave positive results by PCR; no specimen was IF-positive and PCR-negative.

The sensitivity, specificity, positive predictive value, negative predictive value and accuracy of IF and PCR for detection of $P$. carinii in BALF specimens from immunosuppressed patients are shown in table III. PCR with oligoblotting was significantly more sensitive than IF ( $p=0.031)$. The specificity of PCR did not differ significantly from that of IF $(p=0 \cdot 25)$.

Ethidium bromide staining detected a large number of samples that gave positive results by oligoblotting with a sensitivity of $74.3 \%$, specificity of $100 \%$, a positive predictive value of $100 \%$, a negative predictive value of $65.4 \%$ and an accuracy of $82.7 \%$.

\section{Discussion}

The choice of a diagnostic test is based on multiple factors, including the patient population, the volume of specimens being tested by the laboratory and the level of technical expertise required. Recently, Wakefield et al ${ }^{78}$ were able to detect $P$. carinii by PCR amplification of specific DNA in specimens (BALF and induced sputum) that were negative by silver staining. The amplification method is likely to be more efficient than IF, which requires a minimum number of $P$. carinii to give a positive result, ${ }^{17}$ but results are still not conclusive. Indeed, Lipschik et al. ${ }^{18}$ reported that PCR was not significantly better than the conventional staining methods in BALF. PCR for $P$. carinii has been shown to be specific without cross-amplification of non-specific DNA. ${ }^{7,8,18}$ Moreover, Peters et al. suggested that a "strong" PCR signal was consistent with clinical diagnosis of PCP in immunosuppressed patients.

Our study confirmed that PCR was a very sensitive method for detection of $P$. carinii, giving positive results in all cases considered to have PCP. Negative controls (including bronchoscope washing fluid) performed with each PCR run, clearly showed that the method was very specific for $P$. carinii. For the PCR technique to be implemented in a routine diagnostic laboratory, the procedure needs to be improved in convenience and processing time. Our current protocol does not include DNA extraction with phenol-chloroform and precipitation with ethanol; the specimens are processed in a maximum of $2 \cdot 5 \mathrm{~h}$ and conclusive results may be achieved in $24-30 \mathrm{~h}$; this procedure minimises the risk of sample contamination.

The "quantification" of PCR was performed by a limiting dilution technique with an external murine $P$. carinii standard. Digestion and amplification conditions were the same for standards and specimens. This allowed us to carry out a semi-quantitative determination of the number of nuclei present in $1 \mu \mathrm{l}$ of BALF. A signal detectable by both ethidium bromide and oligoblotting denotes the presence of a number of $P$. carinii nuclei $\geqslant 10$; clinical specimens that gave positive results by oligoblotting alone contain 1-10 nuclei. The concentration of organisms in BALF may vary according to the bronchoalveolar lavage procedure used; nevertheless, throughout the study, samples were collected by the same technique and the variation of the recovered sample: instilled volume ratio was minimal. Our results suggest that a positive PCR test (by ethidium bromide and oligoblotting) is less powerful in the diagnosis of $P$. carinii pneumonia than that reported by Peters et al. ${ }^{9} \mathrm{~A}$ different study population could explain this observation. Amplification for $P$. carinii visible by both ethidium bromide and oligoblotting is consistent with clinical disease in immunosuppressed patients without prophylaxis (21 of 22 cases, table II). However, samples from five of 10 immunosuppressed patients who experienced PCP during specific prophylaxis may have given positive results by oligoblotting alone because a lower number of $P$. carinii organisms was present. Samples from three immunosuppressed patients with pneumonia probably not caused by $P$. carinii showed positive $P$. carinii DNA amplification by oligoblotting only. We believe that these three clinical specimens are not false positive $r$ sults. Subclinical colonisation by $P$. carinii may occur in severely immunosuppressed patients. ${ }^{9,18,19}$ Transmission of $P$. carinii from one patient to another could occur during hospitalisation and room-sharing, or from close contact in the community. Furthermore, two other patients, with previous PCP, were PCR-negative for $P$. carinii. These observations, combined with the failure to detect $P$. carinii-specific DNA in post-mortem lungs from non-immunosuppressed individuals, ${ }^{20}$ suggest that recurrent PCP may occur from re-infection rather than reactivation of latent organisms; also, sporadic PCP may occur in immunosuppressed HIV-negative ${ }^{21,22}$ patients or in adults without predisposing illnesses. $^{23}$

In conclusion, we compared the presence of $P$. carinii in BALF as detected by IF technique, with amplification of $P$. carinii DNA by PCR; results correlated in $78.8 \%$ of cases studied. PCR was highly sensitive for the detection of $P$. carinii and detected $P$. carinii more efficiently than IF. The specificity of the two techniques was quite high, particularly in immunosuppressed patients with PCP. Nevertheless PCR has several technical disadvantages and, currently, we do not believe that it is clinically useful for the routine 
detection of $P$. carinii in BALF. In our opinion, $P$. carinii-specific DNA amplification should be used only to test IF-negative BALF samples from patients judged clinically to have PCP. The next step will be to improve the sensitivity (and thus the predictive value) of ethidium bromide staining; preliminary results (unpublished data) suggest that a "nested" PCR could be almost as sensitive and specific as oligoblotting for the detection of $P$. carinii. With future improvements in convenience and processing time, PCR could

\section{References}

1. Peters BS, Beck EJ, Coleman DG et al. Changing disease patterns in patients with AIDS in a referral centre in the United Kingdom: the changing face of AIDS. BMJ 1991 ; 302: 203-207.

2. Jules-Elysee KM, Stover DE, Zaman MB, Bernard EM, White DA. Aerosolized pentamidine: effect on diagnosis and presentation of Pneumocystis carinii pneumonia. Ann Intern Med 1990; 112: 750-757.

3. Montgomery AB. Pneumocystis carinii pneumonia prophylaxis: past, present and future. AIDS 1992; 6: 227-228.

4. Raviglione MC. Extrapulmonary pneumocystosis: the first 50 cases. Rev Infect Dis 1990; 12: 1127-1138.

5. Sparling TG, Dong SR, Hegedus C, Burdge DR. Aerosolized pentamidine and disseminated infection with Pneumocystis carinii. Ann Intern Med 1989; 111: 442.

6. Levine SJ, Masur H, Gill VJ et al. The effects of aerosolized pentamidine prophylaxis on the diagnosis of Pneumocystis carinii pneumonia by induced sputum examination in patients infected with the human immunodeficiency virus. Am Rev Resp Dis 1991; 144 : 760-764.

7. Wakefield AE, Pixley FJ, Banerji S et al. Detection of Pneumocystis carinii with DNA amplification. Lancet 1990; 336: 451-453.

8. Wakefield AE, Guiver L, Miller RF, Hopkin JM. DNA amplification on induced sputum samples for diagnosis of Pneumocystis carinii pneumonia. Lancet 1991; 337: 13781379.

9. Peters SE, Wakefield AE, Banerji S, Hopkin J. Quantification of the detection of Pneumocystis carinii by DNA amplification. Mol Cell Probes 1992; 6: 115-117.

10. Klech H, Pohl W (eds). Technical recommendations and guidelines for bronchoalveolar lavage (BAL): report of the European Society of Pneumology task group on BAL. Eur Respir $J$ 1989; 2: 561-585.

11. Sambrook J, Fritsch EF, Maniatis T. Molecular cloning: a laboratory manual. Cold Spring Harbor, NY, Cold Spring Harbor Laboratory Press. 1989.

12. Wakefield AE, Hopkin JM, Burns J, Hipkiss JB, Stewart TJ, Moxon ER. Cloning of DNA from Pneumocystis carinii. $J$ Infect Dis 1988; 158: 859-862.

13. Sinclair K, Wakefield AE, Banerji S, Hopkin J. Pneumocystis become the most reliable method of detecting $P$. carinii in non-invasive specimens, such as induced sputum. $P$. carinii DNA amplification by PCR may be a valuable epidemiological tool in the initiation and monitoring of PCP chemoprophylaxis.

This work was supported by a grant from the AIDS project (1992) (n. 722.5.26), Istituto Superiore di Sanità, Ministero della Sanità, Rome, Italy. We are grateful to Dr M. Genuardi (Institute of Genetics, Università Cattolica, Rome) for technical support and very helpful discussions.

carinii organisms derived from rat and human hosts are genetically distinct. Mol Biochem Parasitol 1991; 45: 183-184.

14. Sackett DL, Haynes RB, Guyatt GH, Tugwell P. The interpretation of diagnostic data. In: Sackett DL, Haynes RB, Guyatt GH, Tugwell P (eds) Clinical epidemiology: a basic science for clinical medicine. Boston/Toronto/ London, Little, Brown and Company. 1991 : 69-152.

15. Daly LE, Bourke GJ, McGilvray J. Confidence intervals and hypothesis tests: two-group comparisons. In: Daly LE, Bourke GJ, McGilvray J (eds) Interpretation and uses of medical statistics, 4th edn. Oxford, Blackwell Scientific Publications. 1991: 102-138.

16. Antinori A, Murri R, Tamburrini E, De Luca A, Ortona L. Failure of low-dose dapsone-pyrimethamine in primary prophylaxis of Pneumocystis carinii pneumonia. Lancet 1992; 340: 788.

17. Hopewell PC. Pneumocystis carinii pneumonia. Current concepts. In: Sande MA, Volberding PA (eds) The medical management of AIDS. Philadelphia, WB Saunders Company. 1992: 261-283.

18. Lipschik GY, Gill VJ, Lundgren JD et al. Improved diagnosis of Pneumocystis carinii infection by polymerase chain reaction on induced sputum or blood. Lancet 1992; 340: 203-206.

19. Blumenfeld W, McCook O, Holodniy M, Katzenstein DA. Correlation of morphologic diagnosis of Pneumocystis carinii with the presence of pneumocystis DNA amplified by the polymerase chain reaction. Mod Pathol 1992; 5: 103-106.

20. Peters SE, Wakefield AE, Sinclair K, Millard PR, Hopkin J. A search for Pneumocystis carinii in post-mortem lungs by DNA amplification. $J$ Pathol 1992; 166: 195-198.

21. Goesch TR, Gotz G, Stellbrinck KH, Albrecht H, Weh HJ, Hossfeld DK. Possible transfer of Pneumocystis carinii between immunodeficient patients. Lancet 1990; 336: 627.

22. Chave J-P, David S, Wauters J-P, Van Melle G, Francioli P. Transmission of Pneumocystis carinii from AIDS patients to other immunosuppressed patients: a cluster of Pneumocystis carinii pneumonia in renal transplant recipients. AIDS 1991; 5: 927-932.

23. Jacobs JL, Libby DM, Winters RA et al. A cluster of Pneumocystis carinii pneumonia in adults without predisposing illnesses. $N$ Engl J Med 1991; 324: 246-250. 